\title{
Intestinal permeability and diarrhoeal disease in Aboriginal Australians
}

\author{
R H Kukuruzovic, A Haase, K Dunn, A Bright, D R Brewster
}

\begin{abstract}
Background-Northern Territory Aboriginal children hospitalised with acute gastroenteritis have high rates of acidosis, hypokalaemia, and dehydration.

Aims-To determine whether Aboriginal children with and without diarrhoea have greater impairment in intestinal function than non-Aboriginal children, as assessed by increased permeability ratios.

Methods-A descriptive study of 124 children (96 Aboriginal and 28 nonAboriginal) hospitalised with and without diarrhoea. Intestinal permeability was assessed by the lactulose to rhamnose (L-R) ratio from a five hour urine collection.

Results-In Aboriginal children, mean L-R ratios (95\% confidence intervals) were 18.3 (17.1 to 19.6$)$ with diarrhoea and 9.0 (7.3 to 11.0 ) without diarrhoea, and in non-Aboriginal children they were 5.9 (2.8 to 12.3 ) and 4.2 (3.3 to 5.2), respectively. In patients with diarrhoea, $L-R$ ratios were significantly raised when accompanied by acidosis (mean, 22.8 ; 95\% CI, 17.0 to 30.5 ), hypokalaemia (mean, 20.7; 95\% CI, 15.4 to 27.9 ), and $\geqslant 5 \%$ dehydration (mean, 24.3; 95\% CI, 19.0 to 29.6 ) compared with none of these complications (mean, $7.0 ; 95 \% \mathrm{CI}$, 3.5 to 13.8 ).

Conclusion-The high incidence of acidosis, hypokalaemia, and dehydration in Aboriginal children admitted with diarrhoeal disease is related to underlying small intestinal mucosal damage.

(Arch Dis Child 1999;81:304-308)
\end{abstract}

Keywords: intestinal absorption; diarrhoea; Aboriginal children

NHMRC Centre of Clinical Excellence in Aboriginal Health, NT Clinical School, Flinders University and Royal Darwin

Hospital, PO Box 41326, Casuarina, Darwin, NT 0811, Australia

R H Kukuruzovic

A Haase

K Dunn

A Bright

D R Brewster

Correspondence to: Professor Brewster. email: David.Brewster@ health.nt.gov.au

Accepted 28 May 1999

It is well recognised that hospitalised Aboriginal children in the Top End of Australia have more severe manifestations of diarrhoeal disease than non-Aboriginal children. ${ }^{12}$ These include high rates of hypokalaemia, acidosis, and lactose intolerance, particularly in those with underlying malnutrition. We believe that these complications are related to the severity of the underlying small bowel damage, which can be measured non-invasively in urine by the lactulose to rhamnose ( $\mathrm{L}-\mathrm{R})$ test of intestinal permeability-a validated non-invasive test of small bowel mucosal barrier and absorptive functions. ${ }^{3-9}$ Rhamnose recovery is a measure of mucosal absorptive capacity, whereas lactulose permeability reflects barrier function. Mucosal damage or loss of villous surface area alters the rate of permeation of the sugars across the mucosal surface, with decreased rhamnose and increased lactulose recovery resulting in high $\mathrm{L}-\mathrm{R}$ ratios. ${ }^{10}$ After oral administration of the sugar solution, mean urine recovery in normal subjects after five hours is about $0.25 \%$ of the lactulose and $10 \%$ of the rhamnose, giving a mean ratio of $0.025 .{ }^{11}$ For ease of expression, we have multiplied L-R ratios by 100 so that 0.025 becomes 2.5 . The normal mean $\mathrm{L}-\mathrm{R}$ ratio $(95 \%$ confidence intervals) from studies in developed countries using this technique is 2.7 (0.8 to 5.2$),{ }^{7}$ but there is considerable geographical variation in normal adult subjects in the developing world, with mean values varying from 4.9 to 15.6 in a recent review by Menzies et al. ${ }^{12}$

In our study, we used the $\mathrm{L}-\mathrm{R}$ test as a quantitative estimate of the degree of small intestinal damage in hospitalised children with and without diarrhoea. We hypothesised that Aboriginal controls (without diarrhoea) would have abnormal $\mathrm{L}-\mathrm{R}$ ratios as a result of underlying asymptomatic mucosal damage (tropicalenvironmental enteropathy syndrome). In addition, we proposed that Aboriginal children with diarrhoea complicated by acidosis or hypokalaemia would have higher ratios than those without such complications. An acute diarrhoeal infection superimposed on this underlying enteropathy (high $\mathrm{L}-\mathrm{R}$ ratios) would reduce further the lactase levels on the brush border, leading in many cases to osmotic diarrhoea with life-threatening dehydration, hypokalaemia, and acidosis.

A better understanding of this process would assist in decisions about treatment and prevention, so that Aboriginal cases of diarrhoea from remote communities could be managed at health centres without the need for urgent evacuation by aeroplane to hospital.

\section{Patients and methods}

PATIENTS

Our study was carried out at the Royal Darwin Hospital (RDH) in Australia between November 1997 and June 1998. RDH is the tertiary referral centre for the Top End of the Northern Territory serving the capital city as well as remote communities. Aborigines account for $26 \%$ of the catchment population $\leqslant 10$ years of age. Children admitted to hospital with gastroenteritis (more than three fluid bowel actions each day) were eligible for entry into the diarrhoeal group, and those without gastrointestinal or nutritional illnesses were eligible for entry into the control group. The diarrhoeal and control groups were then subdivided into Aboriginal or non-Aboriginal. Children $<3$ months of age and those assessed as being too 


\begin{tabular}{|c|c|c|c|c|c|}
\hline & \multicolumn{2}{|l|}{ Aboriginal } & \multicolumn{2}{|l|}{ Non-Aboriginal } & \multirow{2}{*}{$\begin{array}{l}p \text { Value } \\
(\text { ANOVA) }\end{array}$} \\
\hline & Diarrhoea & Control & Diarrhoea & Control & \\
\hline Number & 44 & 52 & 6 & 22 & \\
\hline Age (months) & $15.3(12.4,18.9)$ & $34.2(26.2,44.6)$ & $23.6(14.3,40.1)$ & $43.5(27.3,69.2)$ & $<0.001$ \\
\hline Mean length of stay (days) & $8.5(7.5,9.8)$ & $6.2(5.0,7.7)$ & $2.9(1.6,5.3)$ & $3.3(2.3,4.7)$ & $<0.001$ \\
\hline Gestation at birth (weeks) & $36.9(35.7,38.1)$ & $37.9(36.8,39.0)$ & $40.0(40,40)$ & $37.2(35.6,38.8)$ & 0.37 \\
\hline Breast fed & $30(68)$ & $20(39)$ & $1(17)$ & $3(14)$ & $<0.0001$ \\
\hline Remote community residence & $42(96)$ & $43(83)$ & 0 & $5(23)$ & $<0.0001$ \\
\hline Birthweight $(\mathrm{kg})$ & $2.7(2.5,2.9)$ & $2.9(2.7,3.1)$ & $3.0(2.4,3.6)$ & $3.1(2.7,3.5)$ & 0.45 \\
\hline Admission weight/age (z-score) & $-2.28(-2.58,-1.98)$ & $-1.34(-1.74,-0.94)$ & $-0.91(-2.01,+0.19)$ & $+0.06(-0.86,+0.98)$ & $<0.0001$ \\
\hline Haemoglobin $(\mathrm{g} / \mathrm{l})$ & $118.5(113.7,123.3)$ & $118.4(114.6,122.2)$ & $122.0(110.4,133.6)$ & $120.3(114.7,125.9)$ & 0.94 \\
\hline Mean corpuscular volume (fl) & $70.9(68.5,73.4)$ & $74.8(72.8,76.8)$ & $76.5(68.0,85.0)$ & $79.9(75.9,83.9)$ & $<0.01$ \\
\hline Serum $\mathrm{K}^{+}(\mathrm{mmol} / \mathrm{l})$ & $2.8(2.5,3.1)$ & $3.9(3.7,4.1)$ & $4.6(3.6,5.6)$ & $3.7(3.5,3.9)$ & $<0.0001$ \\
\hline \multicolumn{6}{|l|}{ Co-morbidities } \\
\hline Pneumonia & $7(16)$ & $6(10)$ & 0 & $2(9)$ & 0.76 \\
\hline Wheezing illness & $4(10)$ & $12(24)$ & 0 & $6(27)$ & 0.17 \\
\hline Chronic suppurative otitis media & $10(23)$ & $8(15)$ & $1(17)$ & 0 & $<0.01$ \\
\hline Urinary tract infection & $10(23)$ & $5(10)$ & 0 & 0 & 0.05 \\
\hline Soft tissue infection & $10(23)$ & $14(27)$ & 0 & $2(9)$ & 0.31 \\
\hline
\end{tabular}

Values are means and $95 \%$ confidence intervals or $\mathrm{n}(\%)$.

unwell by the clinical team were excluded from our study. The control groups could be divided further into those with infections (table 1) and those without (for example, fractures, elective surgery). Written informed consent was obtained from a parent or guardian of the child by the Aboriginal health worker on the research team (AB). Our study was approved by the joint Menzies School of Health Research and $\mathrm{RDH}$ ethics committee.

$\mathrm{L}-\mathrm{R}$ tests were carried out when the child's condition was stabilised, usually on the morning after admission. Children with diarrhoea or malnutrition had repeat testing where feasible when the diarrhoea had settled (four to six days after the initial test). Patients with diarrhoea received standard hospital treatment including oral or intravenous rehydration, as determined by the paediatric staff, who also assessed clinically the degree of dehydration on admission. On admission, patients with diarrhoea had venous blood gases, electrolytes, urine culture, and two stool samples sent for microscopy, culture, and viral antigen detection, but Escherichia coli probes were not done.

\section{PERMEABILITY TESTS}

The ingested probe sugars for permeability testing contained $5 \mathrm{~g}$ lactulose (disaccharide) and $1 \mathrm{~g}$ rhamnose (monosaccharide) in a $100 \mathrm{ml}$ isotonic solution. The test was consid-

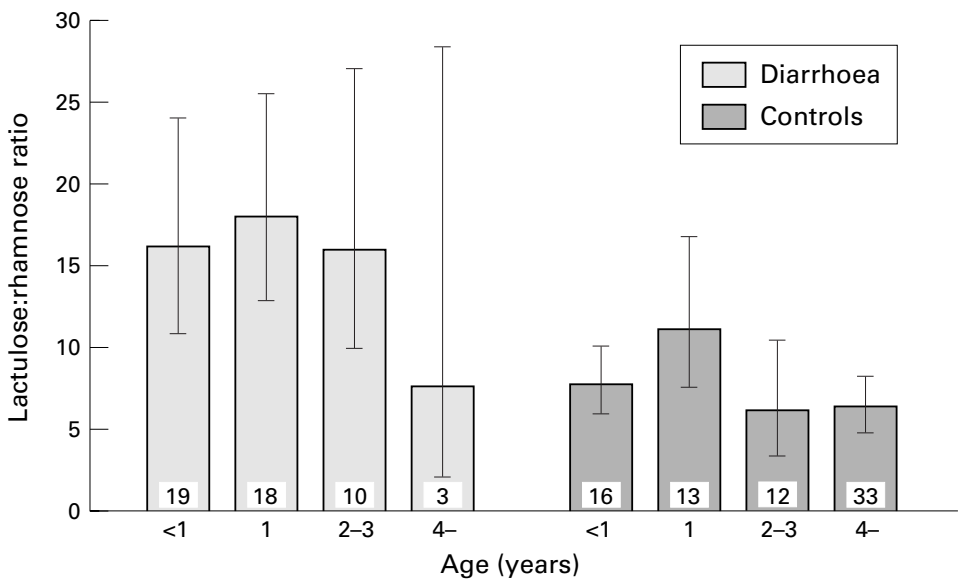

Figure 1 Mean lactulose to rhamnose $(L-R)$ ratios by age. ered a failure if the sugar solution was vomited or refused, or if the urine collection leaked or was contaminated by stool. For the five hour urine collection, a Hollister 24 hour urine bag with a drainage catheter was attached firmly to subjects by sticking plasters. Sugars in urine samples were protected from bacterial degradation by the addition of merthiolate $>10$ $\mathrm{mg} / 100 \mathrm{ml}$ as preservative. A $1 \mathrm{ml}$ sample of urine from the five hour collection was treated with a mixed bed ion exchange matrix, filter sterilised, and diluted 1/10 or more, depending on the urine concentration. The rhamnose and lactulose content of specimens was quantified using the Dionex DX-500 high performance liquid chromatography (HPLC) system, with the anion exchange column PA10, and $40 \mathrm{mM}$ $\mathrm{NaOH} / 0.15 \mathrm{mM}$ zinc acetate as an eluent. ${ }^{13}{ }^{14}$

DATA ANALYSIS

Data were entered and analysed using version 6 of Epi Info (Centers for Disease Control, World Health Organisation). Anthropometric z-scores were calculated using Epinut, which uses National Center for Health Statistics reference standards. For normally distributed variables with homogeneity of variance (Bartlett's test), means were compared by $t$ tests or one way analysis of variance (ANOVA). Variables that were not normally distributed were $\log$ transformed and are presented as geometric means and $95 \%$ confidence intervals (CI). Figures were constructed using PRISM version 3 (GraphPad software), with bars for geometric mean values and $95 \%$ CI values as error bars in all figures. Multiple linear regressions were done using Epi Info, with $r^{2}$ as the proportion of variance explained by the model and the $\mathrm{F}$ statistic as the ratio of the variance explained by the independent variable to the residual mean square variance in the final model. $F$ values of $\geqslant 2.45$ and $\geqslant 3.92$ correspond to $p$ values of $\leqslant 0.05$ and $\leqslant 0.005$, respectively, with 120 degrees of freedom (df) in the denominator and $4 \mathrm{df}$ in the numerator.

\section{Results}

We carried out 148 successful $\mathrm{L}-\mathrm{R}$ urine tests on 124 children. This was out of a total of 234 attempted tests on 154 children, giving a 


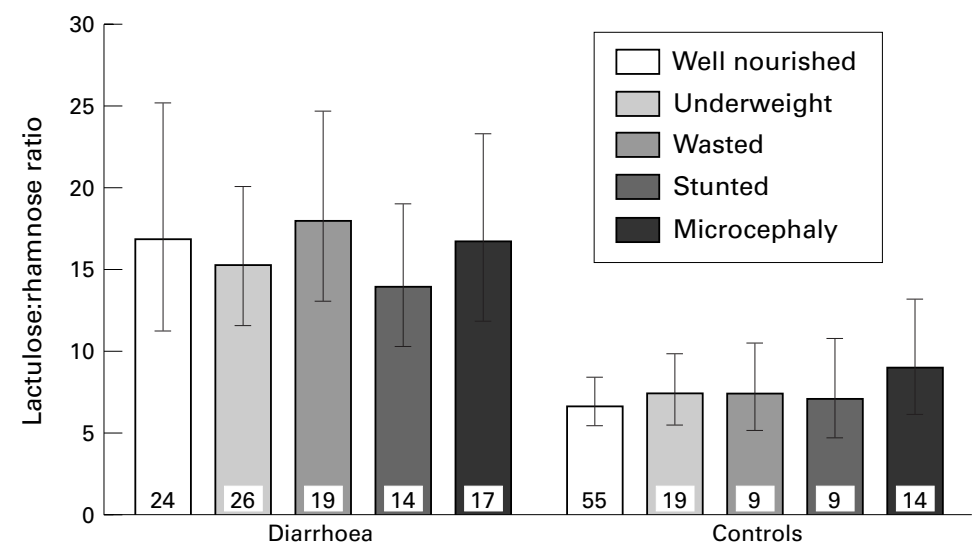

Figure 2 Mean lactulose to rhamnose $(L-R)$ ratios nutritional status.

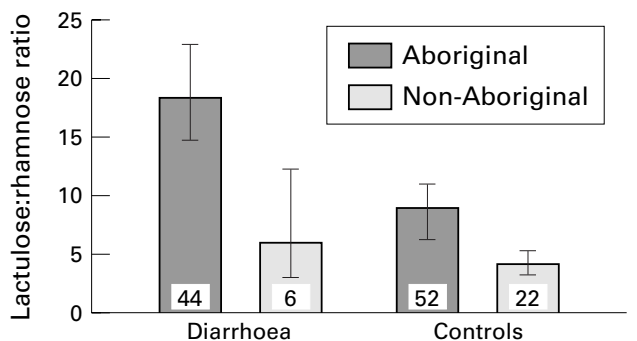

Figure 3 Mean lactulose to rhamnose $(L-R)$ ratios by group.

failure rate of $37 \%$ of tests. This failure rate for five hour urine collection varied from $47 \%$ (32 of 68 ) in girls with acute diarrhoea to $17 \%$ (14 of 82) in non-diarrhoeal controls. Other causes of test failure were vomiting or refusal to drink the probe sugar solution in 21 tests $(9 \%)$.

Table 1 shows admission data for each of the four groups of children in our study. Although there were age and nutritional status differences between groups, figs 1 and 2 show that there were no major differences in mean $\mathrm{L}-\mathrm{R}$ ratios by age and nutritional status. On multiple linear regression $\left(\mathrm{n}=123 ; r^{2}=0.29\right)$, high permeability ratios were significantly associated with diarrhoea and Aboriginal status (partial F tests: 22.7 and 8.1, respectively), but not with age or weight-age z-score (partial F tests: 0.37 and 0.35 , respectively).

Among non-diarrhoeal controls, Aboriginal children had a significantly higher L-R ratio than non-Aboriginal children (mean, 9.0; 95\% CI, 7.3 to 11.0 v mean, 4.2 ; $95 \%$ CI, 3.3 to 5.3 , respectively) (fig 3). The control groups included 36 Aboriginal and 13 non-Aboriginal children admitted because of non-intestinal infections. In non-Aboriginal controls, the geometric mean $\mathrm{L}-\mathrm{R}$ ratio $(95 \% \mathrm{CI}$ ) for those with infections was 5.0 (3.9 to 6.5) compared with 3.2 (2.2 to 4.8) for those without infections, whereas there was no difference in Aboriginal controls as a result of the underlying enteropathy in all Aboriginal children.

In Aboriginal children with diarrhoea, the mean $(95 \% \mathrm{CI})$ serum potassium on admission was 2.7 (1.6 to 3.8$) \mathrm{mmol} /$ litre. Half of the 44 Aboriginal children with diarrhoea were acidotic (serum bicarbonate $<18 \mathrm{mmol} /$ litre), 32 had moderate to severe hypokalaemia (potassium $<3.0 \mathrm{mmol} /$ litre), and 37 were $\geqslant 5 \%$

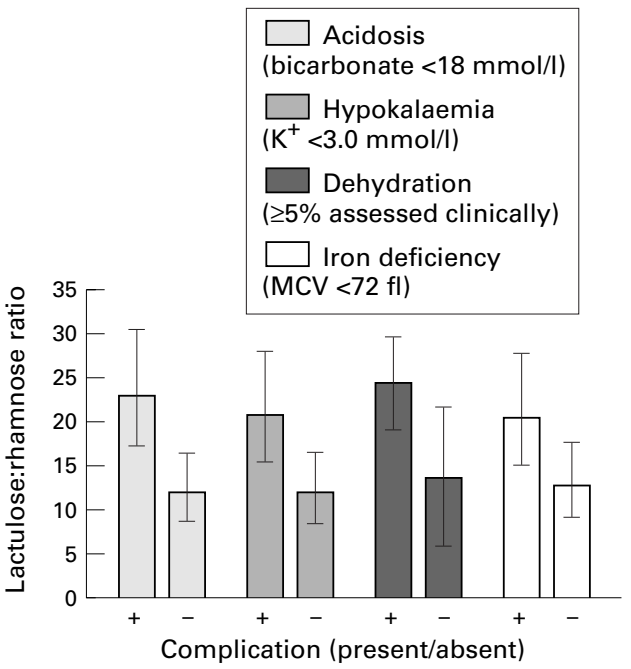

Figure 4 Mean lactulose to rhamnose $(L-R)$ ratios in acute gastroenteritis $(n=50)$ and their relation to acidosis, hypokalaemia, dehydration, and iron deficiency.

dehydrated on clinical assessment. The mean (95\% CI) degree of dehydration by weight gain after 24 hours rehydration in these Aboriginal children was $4.0 \%$ (3.2 to $4.9 \%)$, but this assessment is likely to underestimate the degree of dehydration in children in a catabolic state with ongoing stool losses. Figure 4 shows that acidosis, hypokalaemia, dehydration, and iron deficiency were each associated with significantly higher permeability ratios in patients with diarrhoea than when these conditions were absent. On multiple linear regression of patients with diarrhoea $\left(r^{2}=0.20 ; \mathrm{F}=9.1\right)$, high admission $\mathrm{L}-\mathrm{R}$ ratios correlated independently with acidosis, iron deficiency, dehydration, and hypokalaemia (partial F tests: 6.2, 5.7, 4.6 and 2.9, respectively).

Abnormal permeability ratios were particularly associated with diarrhoea caused by certain enteric pathogens, although numbers of cases are small. Six children with cryptosporidium had the highest mean (95\% CI) ratio of 36.6 (21.4 to 51.8 ), followed by five cases of strongyloides with 25.9 (11.3 to 40.5 ), whereas the remainder of diarrhoeal cases had a mean (95\% CI) ratio of 13.1 (9.8 to 17.6 ). Repeat permeability testing was performed in 18 Aboriginal children on recovery from diarrhoea, and their mean (95\% CI) L-R ratios improved from 19.2 (12.7 to 29.1) on admission to 12.4 (8.3 to 18.3 ) after clinical recovery four to six days later.

\section{Discussion}

We compared intestinal permeability ratios, as a proxy for small bowel mucosal damage, in Aboriginal and non-Aboriginal children with and without diarrhoea. Aborigines with diarrhoea had a high mean L-R ratio (18.3), which is comparable to the mean $(95 \% \mathrm{CI})$ ratio of 17.3 (15.0 to 19.8 ) in children with severe kwashiorkor in Malawi, who had a $30.3 \%$ case fatality. ${ }^{15}{ }^{16}$ Although there is almost no hospital mortality in Darwin for diarrhoeal disease because of the high quality of medical care, Aboriginal children from remote communities 
often require urgent evacuation by air because of severe hypokalaemia, acidosis, and/or dehydration. Our study is the first to demonstrate in Aboriginal children that these complications are associated with an underlying small intestinal enteropathy with abnormally high permeability ratios, consistent with variable degrees of partial villous atrophy.

Among non-diarrhoeal controls, Aboriginal children also had a higher mean $\mathrm{L}-\mathrm{R}$ ratio than non-Aboriginal children. This indicates that an underlying enteropathy in asymptomatic Aboriginal children predisposes them to a more severe acute diarrhoeal illness. Poor living conditions and hygiene standards, with contamination of the weaning diet, can lead to a tropical-environmental enteropathy seen in developing countries and peri-urban slums, which causes partial villous atrophy with malabsorption. ${ }^{17}{ }^{18}$ The poor environmental and hygiene circumstances in remote communities have been well documented in tropical Australia. ${ }^{1920}$ An enteropathy was documented in Aboriginal children in New South Wales in 1971 by Walker-Smith and Reye in a small intestinal biopsy study. ${ }^{21}$ The 44 biopsies in 30 children were all abnormal with thickened ridges or broad villi, but six cases resembled coeliac disease and another eight patients had severe partial villous atrophy, which was thought to be related to repeated episodes of intestinal infections. In our study, we found a mean $(95 \%$ CI) $\mathrm{L}-\mathrm{R}$ ratio in Aboriginal non-diarrhoeal controls of 9.0 (7.3 to 11.0 ), which is even higher than control children in Malawi, ${ }^{15}$ who had a mean $(95 \% \mathrm{CI})$ ratio of 7.0 (5.6 to 8.7$)$ using the same technique. We believe that these high permeability ratios in Aboriginal children without diarrhoea are caused by an underlying severe environmental-tropical enteropathy affecting small intestinal integrity.

In children with diarrhoea, permeability ratios were especially high in those with acidosis, dehydration, iron deficiency, hypokalaemia, and acute strongyloidiasis or cryptosporidiosis. Repeat permeability testing in Aboriginal children upon recovery from diarrhoea showed improved ratios, although they were still significantly higher (mean, 12.4; 95\% CI, 9.8 to 17.6) than for Aboriginal control children (mean, 9.0; 95\% CI, 7.3 to 11.0 ). Slow recovery of mucosal damage occurred notably in association with malnutrition, iron deficiency, strongyloidiasis, and cryptosporidiosis.

Initially, we were rather surprised to discover that poor nutritional status was not a significant contributor to abnormal permeability in our patients (fig 2). However, this is a consistent finding now in over 350 hospitalised children in Darwin whose $\mathrm{L}-\mathrm{R}$ ratios have been measured. We believe that this can be explained by the following: (1) none of our subjects had severe malnutrition (kwashiorkor or marasmus) and; (2) in this hospital context, enteric infection and hygiene-environmental factors are predominant in affecting small intestinal mucosal function in Aboriginal children. It is still likely that mucosal damage with malabsorption is contributing significantly to poor growth in asymptomatic children in remote
Aboriginal communities, but we could not demonstrate this in a hospital setting.

The intestinal mucosal damage in controls measured by abnormal $\mathrm{L}-\mathrm{R}$ ratios in our study has important health implications for Aboriginal children. In Gambian community studies, ${ }^{822}$ high permeability ratios and lactose malabsorption contributed to $48 \%$ of the growth deficit in apparently well children. Iron deficiency is another factor contributing to abnormal permeability, as a result of effects on mucosal function, ${ }^{23}$ which was confirmed in our study in iron deficient Aboriginal children. The high burden of disease and problems with iron compliance make it difficult to reduce the high rates of iron deficiency in Aboriginal community children. ${ }^{24}$ Further studies are needed to look at how to hasten intestinal repair in Aboriginal children, who cannot afford prolonged periods of impaired intestinal absorption.

Although low lactose formulas are not advised routinely in the management of acute gastroenteritis, ${ }^{25}$ lactose intolerance with severe osmotic diarrhoea is encountered so commonly in Aboriginal children in Darwin that low lactose formulas are used routinely in hospital. This practice is underpinned by two randomised controlled trials in hospitalised Aboriginal children with diarrhoea, documenting significantly greater weight gain on a low lactose formula than with a normal milk formula. ${ }^{26}{ }^{27}$ Recent studies have showed that malnutrition and enteropathy independently cause reductions in lactase specific mRNA. ${ }^{28}$ When the lactase threshold is exceeded, unabsorbed lactose in the small bowel can lead to osmotic diarrhoea, with loss of fluid and electrolytes in the stool, but it may also contribute to acidosis through small bowel bacterial overgrowth, with systemic absorption of organic acids produced by fermentation of unabsorbed sugars. Gracey and Stone have documented small bowel bacterial overgrowth in Aboriginal children. ${ }^{29}$

In spite of high quality nursing care and two dedicated research staff for permeability testing, we found that five hour urine collection in young children with acute gastroenteritis was associated with high failure rates, as a result of poor adhesion of urine bags to the perineum and urine spillage or cross contamination from profuse diarrhoea. Because failures could bias our results, we have compared the characteristics of children with failed versus successful permeability tests and found that ages and severity of diarrhoea were similar (data available on request).

Intestinal permeability studies on urine have been reported previously in children with acute diarrhoea, but with little mention of failure rates. ${ }^{30-33}$ However, a recent Guatemalan study ${ }^{34}$ has reported high failure rates in non-acutely ill children of $31.6 \%$ (73 of 231). In permeability studies in Malawi, ${ }^{15}{ }^{35}$ one author (DRB) encountered similar difficulties with urine collection in kwashiorkor cases and resorted to overnight urine collection, when urine bags were less likely to come off. From the additional experience in the Darwin setting, we conclude 
that $\mathrm{L}-\mathrm{R}$ testing on urine is not a feasible outcome measure for a clinical trial in young children with diarrhoea. Consequently, we sought a more reliable way of doing the test without the need for prolonged urine collection. Permeation rates of the test sugars differ between jejunum and ileum, so urine collections shorter than five hours give falsely low ratios. ${ }^{36}$ Five studies ${ }^{37-41}$ have reported timed blood samples for dual sugar ratios measured by HPLC, so we felt that $\mathrm{L}-\mathrm{R}$ ratios in blood would be more reliable than in urine for children with diarrhoea. Our experience with $\mathrm{L}-\mathrm{R}$ ratios on a timed blood test compared with urine will be the subject of another report (A Haase et al, 1999, unpublished).

In conclusion, we have documented that hospitalised Aboriginal children from remote communities in northern Australia have abnormal intestinal permeability even without diarrhoea, consistent with an underlying partial villous atrophy related to environmentaltropical enteropathy. Small intestinal mucosal damage is also an important factor in the high rates of osmotic diarrhoea with dehydration, hypokalaemia, and acidosis in Aboriginal children with acute gastroenteritis. Further research into this issue could improve our understanding and help design appropriate treatment and preventive measures to keep Aboriginal children with diarrhoea out of hospital and growing normally.

The authors thank the nursing staff of the isolation paediatric ward at Royal Darwin Hospital for their collaboration in this project.

1 Ruben AR, Walker A . Malnutrition among rural Aboriginal children in the Top End of the Northern Territory. Med $\mathcal{f}$ Aust 1995;162:400-3.

2 Walker AC, Harry JG. A survey of diarrhoeal disease in malnourished Aboriginal children. Med F Aust 1972;1:904-11.

3 Uil JJ, van Elburg RM, van Overbeek FM, Mulder CJ, VanBerge Henegouwen GP, Heymans HS. Clinical implications of the sugar absorption test: intestinal permeability test to assess mucosal barrier function. Scand $\mathcal{f}$ Gastroen terol Suppl 1997;223:70-8.

4 Bjarnason I, Macpherson A, Hollander D. Intestinal permeability: an overview. Gastroenterology 1995;108:156681 .

5 Meddings JB, Gibbons I. Discrimination of site-specific Meddings JB, Gibbons I. Discrimination of site-specific alterations in gastrointestinal
Gastroenterology 1998;114:83-92.

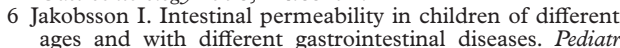
ages and with different gast

7 Travis S, Menzies I. Intestinal permeability: functional assessment and significance. Clin Sci (Colch) 1992;82:47188.

8 Lunn PG, Northrop Clewes CA, Downes RM. Intestinal permeability, mucosal injury, and growth faltering in Gambian infants. Lancet 1991;338:907-10.

9 Ford RP, Menzies IS, Phillips AD, Walker-Smith JA, Turner $M$. Intestinal sugar permeability: relationship to diarrhoeal disease and small bowel morphology. 7 Pediatr Gastroenterol Nutr 1985;4:568-74.

10 Hollander D. The intestinal permeability barrier. A hypothesis as to its regulation and involvement in Crohn's disease. Scand $\mathcal{f}$ Gastroenterol 1992;27:721-6.

11 Menzies IS, Laker MF, Pounder R, et al. Abnormal intestinal permeability to sugars in villous atrophy. Lancet nal permeability

12 Menzies IS, Zuckerman MJ, Nakujam WS, et al. Geography of intestinal permeability and absorption. Gut 1999;44: 483-9.

13 Kynaston JA, Fleming SC, Laker MF, Pearson AD. Simultaneous quantification of mannitol, 3-O-methyl glucose, and lactulose in urine by HPLC with pulsed electrochemical detection, for use in studies of intestinal permeability. Clin Chem 1993;39:453-6.

14 Willems D, Cadranel S, Jacobs W. Measurement of urinary sugars by HPLC in the estimation of intestinal permeability: evaluation in pediatric clinical practice. Clin Chem 1993;39:888-90.
15 Brewster DR, Manary MJ, Menzies IS, O'Loughlin EV, Henry RL. Intestinal permeability in kwashiorkor. Arch Dis Child 1997;76:236-41.

16 Brewster DR, Manary MJ, Graham SM. Case management of kwashiorkor: an intervention project at 7 nutritional rehabilitation centres in Malawi. Eur F Clin Nutr 1997;51: 139-47.

17 Fagundes Neto U, Martins MC, Lima FL, Patricio FR, Toledo MR. Asymptomatic environmental enteropathy among slum-dwelling infants. $\mathcal{F}$ Am Coll Nutr 1994;13:516.

18 Lindenbaum J. Tropical enteropathy. Gastroenterology 1973; 64:637-52.

19 Torzillo P, Rainow S, Pholeros P. Environmental health in remote aboriginal communities. f $R$ Soc Health 1993;113: 310-12

20 Gracey M, Williams P, Houston S. Environmental health conditions in remote and rural aboriginal communities in western Australia. Aust N Z F Public Health 1997;21:51118.

21 Walker-Smith JA, Reye RD. Small intestinal morphology in aboriginal children. Aust NZ Y Med 1971;1:377-84.

22 Northrop Clewes CA, Lunn PG, Downes RM. Lactose maldigestion in breast-feeding Gambian infants. F Pediatr Gastroenterol Nutr 1997;24:257-63.

23 Berant M, Khourie M, Menzies IS. Effect of iron deficiency on small intestinal permeability in infants and young children. F Pediatr Gastroenterol Nutr 1992;14:17-20.

24 Kruske SG, Ruben AR, Brewster DR. An iron treatment trial in an Aboriginal community: improving nonadherence. F Paediatr Child Health 1999;35:153-8.

25 Lifschitz CH. Use of milk in infants with diarrhea. Arch Latinoam Nutr 1992;42:48S-50S

26 Brand JC, Miller JJ, Vorbach EA, Edwards RA. A trial of lactose hydrolysed milk in Australian Aboriginal children. Med F Aust 1977;2:10-13.

27 Mitchell JD, Brand J, Halbisch J. Weight-gain inhibition by lactose in Australian Aboriginal children. A controlled trial of normal and lactose hydrolysed milk. Lancet 1977;i: $500-2$.

28 Nichols BL, Dudley MA, Nichols VN, et al. Effects of malnutrition on expression and activity of lactase in children. Gastroenterology 1997;112:742-51.

29 Gracey M, Stone DE. Small-intestinal microflora in Australian Aboriginal children with chronic diarrhoea. Aust N Z Ұ Med 1972;2:215-19.

30 Dupont C, Moreno JL, Barau E, Bargaoui K, Thiane E, Plique $\mathrm{O}$. Effect of diosmectite on intestinal permeability changes in acute diarrhea: a double-blind placebocontrolled trial. F Pediatr Gastroenterol Nutr 1992;14:41319.

31 Roy SK, Behrens RH, Haider R, et al. Impact of zinc supplementation on intestinal permeability in Bangladeshi children with acute diarrhoea and persistent diarrhoea syndrome. F Pediatr Gastroenterol Nutr 1992;15:289-96.

32 Sullivan PB, Lunn PG, Northrop Clewes C, Crowe PT, Marsh MN, Neale G. Persistent diarrhea and malnutrition-the impact of treatment on small bowel structure and permeability. $\mathcal{f}$ Pediatr Gastroenterol Nutr 1992;14:208-15.

33 Weaver LT, Chapman PD, Madeley CR, Laker MF, Nelson R. Intestinal permeability changes and excretion of microorganisms in stools of infants with diarrhoea and vomiting. Arch Dis Child 1985;60:326-32.

34 Goto K, Chew F, Torun B, Peerson JM, Brown KH. Epidemiology of altered intestinal permeability to lactulose and mannitol in Guatemalan infants. 7 Pediatr Gastroenterol Nutr 1999;28:282-90.

35 Brewster DR, Manary MJ, Menzies IS, Henry RL, O'Loughlin EV. Comparison of milk and maize-based diets in kwashiorkor. Arch Dis Child 1997;76:242-8.

36 Elia $M$, Behrens R, Northrop C, Wraight P, Neale G. Evaluation of mannitol, lactulose and 51Cr-labelled ethylenediaminetetra-acetate as markers of intestinal permeability in man. Clin Sci (Colch) 1987;73:197-204.

37 Cox MA, Iqbal TH, Cooper BT, Lewis KO. An analytical method for the quantitation of mannitol and disaccharides in serum: a potentially useful technique in measuring small intestinal permeability in vivo. Clin Chim Acta 1997;263: $197-205$.

38 Sorensen SH, Proud FJ, Rutgers HC, Markwell P, Adam A, Batt RM. A blood test for intestinal permeability and function: a new tool for the diagnosis of chronic intestinal disease in dogs. Clin Chim Acta 1997;264:103-15.

39 Fleming SC, Duncan A, Russell RI, Laker MF. Measurement of sugar probes in serum: an alternative to urine measurement in intestinal permeability testing. Clin Chem 1996;42:445-8.

40 Fleming SC, Kynaston JA, Laker MF, Pearson AD, Kapembwa MS, Griffin GE. Analysis of multiple sugar probes in urine and plasma by high-performance anion-exchange chromatography with pulsed electrochemical detection. Application in the assessment of intestinal permeability in human immunodeficiency virus infection. $f$ Chromatogr 1993;640:293-7

41 Cox MA, Lewis KO, Cooper BT. Measurement of small intestinal permeability markers, lactulose, and mannitol in serum: results in celiac disease. Dig Dis Sci 1999;44:402-6. 